NOTAS

\title{
DE LA EDUCACIÓN OFICIAL CONSERVADORA A LA UTOPÍA DE LA IMAGINACIÓN Carlos de la Isla*
}

Sialguna afirmación se puede expresar con cierta firmeza en estas postrimerías del siglo XX es que toda afirmación ha de ser precavida y modesta. Esto es especialmente válido para el campo de la filosofía y de las ciencias sociales.

Desde que la escuela socrática comenzó a obtener un verdadero triunfo, a favor de la razón sobre la fuerza del drama, de la tragedia y de la comedia, los pensadores de Occidente tomaron muy en serio la idea de que la razón puede generar toda la verdad. Se lanzaron con orgullo y entusiasmo a elaborar los grandes sistemas ordenados del pensamiento que pretendían evidenciarlo todo.

Fueron como maestros clarividentes anunciadores de la verdad. La educación consistía (y en gran medida sigue consistiendo) en entender, retener y repetir lo que había dicho el "profeta de

* Departamento Académico de Estudios Generales, ITAM. la verdad" y porque él lo había dicho. Esto permanecía con carácter de mito y ritual hasta que otro gran maestro lo cuestionaba o destruía y construía un nuevo "edificio del pensamiento verdadero", que pasaba a las aulas para ser otra vez entendido y repetido.

La permanencia secular de los sistemas de verdad se debe en buena parte al proceso educativo tendiente a la conservación y a la reproducción de los pensamientos de los "grandes"; es decir, a la educación por la memoria, ya que la misma razón se ejercita en función de retener y recordar.

Además, la "verdad en turno" se revestía de racionalidad y se presentaba con imágenes esperanzadoras que usaban los poderes públicos, las escuelas y los grupos dominantes en la lucha por su apropiación. Se apropian de la "verdad" y con ella del poder que le es exclusivo y excluyente. Y los partidos más opuestos en las facciones más antagónicas manejan su jus- 
NOTAS

tificación siempre "en nombre de la verdad".

Consecuencia: los grandes sistemas explicativos, así apropiados e interpretados, presentan grietas o al menos resquicios suficientes para dejar ver su vulnerabilidad. Además, el manejo arbitrario de la verdad ha producido una negación de credibilidad en la palabra y sus contenidos: iquién capta la verdad del contenido de la palabra "libertad"? ¿Quién cree o al menos entiende el contenido y esperanza de la palabra "justicia"? ¿Cómo se ha difundido el término "democracia"? Con adjetivos, sin adjetivos, con sustancia y accidentes, como participación de la sociedad civil y fuerte Estado y con todas las demás atribuciones caprichosas y hasta absurdas, porque finalmente lo que falta es la acción significada por el verbo democratizar que da la verdadera sustancia al contenido de la democracia.

¿Qué decir de las palabras soberanía, derecho, autoridad, obligación, valor y dignidad? ¿Qué expresan en el discurso oficial, en el diálogo ordinario?

¿Es este lenguaje instrumento de poder? ¿Es la vaciedad de contenido del lenguaje lo que lo convierte en instrumento de arbitrario manejo de dominación?

La quiebra de los grandes sistemas tradicionales con aspiraciones de explicación omnicomprensiva, y el empleo del lenguaje, por esencia comunicador, para racionalizar y justificar las posturas más extremas han puesto en evidencia la crisis de la educación en torno a la memoria. Educación como sistema dirigido a la conservación y perpetua- ción de "valores" y "poderes"; como sistema que ha insistido en el aprendizaje de palabras que expresan "verdades" que hay que conservar, recordar, repetir, aunque carezcan de un contenido sustantivo.

El mundo del siglo XX parece acercarse a las postrimerías del milenio con incertidumbre y angustia; en pocos casos con satisfacción y luminosidad; existe un claro desconcierto.

Hecho el balance final sobre el progreso humano no parece nada clara la inclinación favorable. Por el contrario, la expectativa orgullosa del siglo pasado sobre el triunfo del hombre hasta el desplazamiento de Dios parece que ha sufrido su correspondiente humillación.

Los mitos del progreso heredados por genética histórica, en especial del siglo XIX, se han develado: el continuo progreso del género humano asegurado por la ley inexorable del desarrollo dialéctico de la idea o del desarrollo también dialéctico de la materia y de la historia en evolución constante, contrastan con la realidad de un mundo dividido hasta la lucha sangrienta por intereses étnicos, políticos y económicos sin que importe el sacrificio de las personas. Se trata de una idea del progreso que contrasta con la expresión dominante de subdesarrollo económico o político o ético e ideológico o, finalmente, subdesarrollo humano.

Los mitos de las teorías económicas del liberalismo y del socialismo, heredados por el mismo proceso con la promesa de un final feliz, contrastan con las grandes diferencias de clases entre países de diversos mundos: países 
del primer mundo, dominadores de la abundancia, que no sólo usan a los países subdesarrollados sino que los mantienen en esa situación de dependencia (financiera, tecnológica, cultural) que significa sumisión o muerte. Ejemplos:

Promesa del liberalismo: "el bien individual redunda en el bien colectivo para el logro del bienestar humano", contrasta con la incontrolable riqueza inactiva de unos y el hambre de tantos. Promesa del socialismo: reino de la libertad, de la creatividad, de la justicia de acuerdo con las necesidades... que tanto contrasta con esa realidad que ha provocado el derrumbe del socialismo real.

Los movimientos de protesta de 1968 en los más diversos ámbitos sociales, pero en especial en las universidades, se han interpretado con razón como un rechazo universal a los sistemas que usan a las personas como piezas en el juego del poder. Es comprensible que la filosofía de Marcuse, que sostenía la legitimidad de la destrucción como un fin en sí mismo por la calidad de la corrupción que destruía, fuera la bandera ideológica de la gran protesta.

El movimiento del 68 fue el gran clamor en defensa de la subjetividad, a favor del ser personal y en contra de los sistemas dominantes. Fue significativo, muy significativo que uno de los lemas preferidos fuera "la imaginación al poder". Viniendo de las universidades la invitación al cambio significaba la sensatez.

Mito de teoría política: gobierno benefactor, árbitro justo, tan opuesto a la fórmula: orden-obediencia-coerción que se afirma y agiganta para beneficio del "benefactor".

El mito del poder de la razón tan reverenciado en el siglo XIX, que lograría la igualdad y la unidad entre los hombres bajo el único imperio de la ciencia y de la técnica, contrasta mucho con la angustia y el temor reinantes. Es el poder de la razón, que no aparece nada claro en el inventario del desperdicio y el hambre, de la explotación de los recursos, del respeto a la nat uraleza y de la convivencia humana.

Develados estos mitos del siglo XIX a tan alto precio, la reacción se ha desencadenado en diferentes direcciones: actitudes en contra de lo establecido; pesimismo especialmente entre los jóvenes, ante un mundo manejado por razones de dominio, ante un futuro en el que no hay objetivos que valgan la pena; subjetivismo axiológico que ha conducido al pleno relativismo hasta llegar al cinismo o al nihilismo; tendencia al pasado como en un nuevo renacimiento para aferrarse a la seguridad de lo vivido.

Es en este contexto que aparece enteramente válida la opción consistente en el desarrollo de la imaginación para inventar, fomentándola al menos con la misma intensidad con que se ha privilegiado al desarrollo de la memoria en la educación tradicional.

Los problemas que el mundo afronta y que tienden a agigantarse en los planos políticos, económicos, sociales, ecológicos, poblacionales... hacen pensar no sólo en crisis, sino en situaciones graves, permanentes y de difícil solución. 
NOTAS

Parece que la participación de los ilustrados que han tenido poder de decisión y han propuesto programas de desarrollo en las dos últimas décadas, si se ha de juzgar por los resultados, no ha sido afortunada.

Esta realidad actual que por su evidencia no exige una complicada demostración, robustece la idea de que las soluciones para el futuro deben ser aportadas, inventadas a la medida de las necesidades con mucha imaginación.

Desde la perspectiva del cambio del presente lo único cierto que podemos decir del futuro es que resulta enteramente impredecible. Por la incertidumbre del futuro ya no es posible concebir la formación humana como conjunto de conocimientos, hábitos y destrezas para realizar con calidad el quehacer de hoy; es decir, ya no es posible sólo memorizar para repetir el pasado y el presente.

Es indispensable afirmar la formación permanente hecha de la capacidad analítica, crítica e imaginativa para inventar el futuro o por lo menos para afrontar con estatura y dignidad lo que venga. Ya no hay cabida para los copistas o imitadores. Ahora, lo queramos o no, estamos siendo invitados o tal vez lanzados por la necesidad a la originalidad. Los científicos y técnicos que avanzarán cómodamente al futuro serán los que hayan acertado en el ejercicio que fortalece la capacidad de ordenar, juzgar, inducir o deducir con rectitud, los que hayan preferido el camino de la modesta sabiduría al de la erudición.
El objetivo de la educación, cuando no se ha emplea to como instrumento de control, siempre ha sido propiciar el desarrollo integral y armónico de las potencialidades que ya existen en todo ser humano. El cultivo de la imaginación, de la reflexión, de la inventiva requiere una modificación sustancial del sistema tradicional que se propone el aprendizaje, la conservación y repetición de los conocimientos programados. Como se ha dicho, este sistema funciona en torno a la memoria. Es, por lo tanto, un mecanismo conservador.

Los métodos que emplea son bien conocidos, pero es útil tenerlos presentes para poner énfasis sobre las diferencias y hasta oposiciones con el sistema que aquí se sugiere. Su medio favorito en la transmisión del saber, es la exposición docente con tono profético o velado por la modestia, pero finalmente impositivo y autoritario. El valor del mensaje está revestido de "cientificidad" y de "verdad demostrada". Consecuencia: el alumno debe recibir y conservar; puede interrogar, pero no con espíritu de cuestionamiento, sino para apoyar mejor el mensaje recibido. La relación es vertical: la verdad desciende de la cátedra. El mejor maestro es el más fiel transmisor. El mejor alumno es el que tiene mayor capacidad receptiva para captar la teoría completa. Después éste se convierte en maestro para repetir el proceso, y así se conserva la tradición que mantiene el conjunto de las mismas verdades, de las mismas relaciones sociales, de los mismos beneficios y beneficiados. 
Así se han mantenido los grandes sistemas de verdad por apropiación, los sistemas sociales, políticos, económicos dominantes, los que manifiestan las grietas profundas y que han sido incapaces de resolver los problemas más apremiantes.

Parece, pues, que la alternativa es el desarrollo de la imaginación. El método es radicalmente distinto. Empieza con el lenguaje, que consiste en la expresión de acciones comunicantes, en las que poco o nada importa el agregado o la etiqueta de la palabra. (Los griegos pensaban sin nombres, dice Heidegger.) Es lo que se podría llamar comunicación sustantiva.

Dialógico es el término más aproximado para significar esta actividad educacional dirigida a inventar, a descubrir. La raíz de la palabra es la primitiva: logos, que proviene de legein, que significa decir; y decir es mostrar o manifestar. Dia significa "a través". Este diálogo es un discurrir a través de lo que se muestra. El punto de partida es el logos o mostración de la realidad sin interrupción ni calificación. (Sin exégesis ni hermenéutica preconcebidas.) Es expresión original que se ofrece al discurso múltiple y que propicia la visión personal, la perspectiva de cada sujeto, los matices captados y proyectados por los lentes muy singulares.

Ya los primeros acercamientos escolarizados a la realidad tienen la intención de captarla y expresarla (fines de la ciencia y del arte). El niño, el adolescente y el joven son invitados a apresar su segmento del mundo que les rodea, que se les muestra, y a ex- presarlo con todos los matices de la riqueza subjetiva de la interioridad personal. Este método es una invitación a hacer ciencia y a producir arte a la vez. iQué diferente a la orden de copiar lo que se ve y repetir lo que se oye!

Discurrir la realidad tal como se muestra desde tales perspectivas ino conduciría a descubrir segmentos nuevos, diferentes? ¿No podrán captarse dimensiones nunca conocidas para construir nuevas utopías como visiones que hacen posible lo deseable?

Estas hipótesis del discurso de la imaginación sobre la realidad suelen atacarse con el argumento de racionalismo. Pero ino se han jugado ya demasiado las cartas del realismo, del positivismo, del materialismo, de todos los ismos? Resulta, pues, más que legítimo explorar el campo de lo desconocido, que muy probablemente es más amplio que el de lo conocido. La invitación es a incursionar en el mundo de las posibilidades que pueden mostrar caminos diferentes, tal vez más seguros y mejores.

Presentar las opciones existentes como las únicas reales es una trampa que ponen aquellos pocos a quienes conviene perpetuar lo establecido.

La universidad, que por su misión debe conservar y acrecentar la luz, es señaladamente responsable de favorecer la invención para caminar al frente, hacia la oscuridad del futuro. Debe generar el cultivo del conocimiento analítico, crítico y aún del intuitivo. En este proceso el maestro no es el dictador de datos, problemas, interpretaciones y soluciones, sino el compañero que camina 
junto al discípulo, que lo invita y anima a pensar y a descubrir.

El maestro no considera al alumno ni retrasado ni inferior, sino un ser humano con la capacidad del genio, creador, inventor, artista... y que sólo espera el impulso o al menos desea no ser recluido en las concepciones cuadradas y rígidas del saber común, obligado y oficial.

La pedagogía de la imaginación parte de una antropología diferente, con un criterio muy distinto de apreciación: juzga muy superior el despuntar de un pensamiento original a la repetición textual y exacta del discurso escolar por brillante que sea. Incursionar en lo desconocido, imaginar aun lo imposible para construir utopías... es la actitud inspiradora de esta relación.

La universidad podrá aportar más luz si, además de ofrecer programas de carreras que responden a las necesidades sociales presentes y a las demandas de un mercado singular, también propone programas con un predominio de seminarios abiertos al ejercicio del descubrimiento y de la imaginación.

Educar la imaginación para la investigación, quehacer también esencial de la universidad, implica descubrir nuevos horizontes para recuperar la capacidad de asombro, de admiración que conduce al descubrimiento. Recuperar; preservar, porque es herencia universal que se ha ido degradando, el impulso-amor hacia el conocimiento de la naturaleza y que domine al impulso-poder que ha engendrado la neurosis contra la naturaleza.
Fomentar el ingenio de la investigación lleva consigo en muchos casos la pedagogía de una sabia ignorancia que prescinde de supuestos, de innumerables supuestos que definen los procedimientos que han conducido a las concepciones del mundo, de la sociedad y de la vida que ahora nos rigen.

¿Por qué suponer una antropología tan empobrecida que muestra al hombre egoísta, violento, destructivo, acaparador, regido por thanatos o a la necrofilia? Respuesta racionalista o empirista: "lo que es evidente no se supone", pero ino se aceptaban como evidentes la inmovilidad de la Tierra, el funcionamiento mecánico de la naturaleza, la objetividad de los fenómenos físicos?

iSi Copérnico, Galileo, Einstein, Heinseberg... hubieran aceptado como evidentes e incuestionables aquellas "supuestas evidencias"! En el campo político seguiría reinando la monarquía absoluta si se aceptara, aún hoy, el "evidente supuesto", según Hobbes, de que el hombre es lobo para el hombre.

Éste es el grave riesgo de la veneración de los supuestos que se afirman en la educación de la memoria.

$\mathrm{La}$ investigación del futuro ha de tender más a descubrir desde los primeros pasos, cuando menos en un buen número de aventuras del pensamiento, lo que es el hombre (icuántos siglos estudiando al hombre y cuánto misterio aún en la oscuridad del inconsciente, de la conciencia y de su mismo ser!). Y el mismo procedimiento deberá seguirse para elucidar problemas de convivencia, de justicia y 
libertad en la geografía del poder; de los valores de los hombres, de sus protestas, de su clamor por la vida, de su repudio a la destrucción y al hambre.

En cierto sentido ésta es una investigación pura, por incondicionada, aunque también puede resultar, como ya ha resultado en otras épocas de la historia, la más aplicable y aplicada. Este sentido de investigación no sugiere la sustitución o desplazamiento de la que ya se realiza con honradez y debe fomentarse según las exigencias de las necesidades sociales. Se señala como alternativa: distinto procedimiento en su dirección y sentido: ejercicio de la imaginación y de la intuición hacia lo imprevisible y lo desconocido de esa realidad que somos y nos rodea, de la que nuestros mejores científicos saben muy bien lo poco que saben.

Por todo esto pienso que es legítimo afirmar que las universidades que abran un mayor espacio a la pedagogía de la imaginación y, por lo tanto a la investigación y a la creación, estarán más firmes en el presente y de cara al futuro.

La modificación de la pedagogía en torno a la memoria, que tiende a conservar y repetir las estructuras existentes parece difícil porque la educación ha sido un instrumento de poder y está ligada a la práctica social del poder. Sin embargo, frente al futuro incierto y problemático el desarrollo de la imaginación para inventar y crear se presenta como alternativa obligada, como una tarea con carácter de reto y compromiso, especialmente para las es- cuelas que decidan cumplir su responsabilidad social. Ejercicio difícil, pero de eso se trata: que la imaginación construya la utopía de hacer posible lo deseable.

Si se educa la imaginación con imaginación, si se fomenta todo impulso creativo, al primer triunfo se superará el miedo oficial a la libertad, que ha conducido a una política de mecanismos de control y será posible y hasta necesario el tan deseado tránsito del Estado premoderno al moderno.

El político con imaginación comprenderá que el buen gobierno, el que tiene permanencia y legitimidad, es el gobierno de las personas y para las personas que piensan, cuestionan, deciden, participan, y que es engañoso $\mathrm{e}$ ilegítimo el ejercicio del poder sobre individuos que conforman una masa de impulsos, tal vez controlables pero también impredecibles.

Se descubrirán procedimientos nuevos basados en ideas nuevas para construir una sociedad sana con más oportunidades de desarrollo humano para todos. Esto supone un empleo más justo y racional de los recursos y una distribución más equitativa de esta riqueza real y potencial que ahora favorece a $\tan$ pocos.

El empresario de imaginación cultivada fácilmente comprenderá, sin autojustificaciones artificiales, que la ganancia y el beneficio sólo son verdaderos cuando sc comparten. Fácilmente podrá inventar esquemas, modelos y mecanismos que produzcan un crecimiento económico que se convierta en desarrollo social. Compren- 
NOTAS

derá, desde una muy diferente jerarquía de valores, que el único antídoto de la lucha de clases es la justicia social.

El trabajador de todas las especificaciones (marginado, subempleado, comercializado, especializado) ejercitará su imaginación, porque ya la posee, para lograr que aumente la productividad en la empresa que lo considere y valore como persona y no como fuerza de trabajo. Creará una tecnología a la medida de sus necesidades, del estilo de sus habilidades y logrará una existencia digna, libre y humana. El trabajador expresará al artista creador que en su interior lucha por manifestarse.

Las grandes vertientes social, política, económica que discurran por cauces construidos con nuevas concepciones y nuevas perspectivas, permitirán pensar una sociedad desarrollada, educada y con un potencial humano que modificará las orientaciones del futuro en todas las dimensiones: sociales; culturales, ecológicas, poblacionales, económicas, políticas e internacionales.

Soy consciente de que casi todas las soluciones a los problemas actuales suenan a utopías irrealizables. Sin embargo, es saludable pensar que la disyuntiva (repetir la misma dirección y sentido por el ejercicio de la memoria) puede ser desastrosa. 